\title{
Word Formation Used In $J+$ Newspaper
}

\author{
Cicih Nuraeni \\ Sekolah Tinggi Ilmu Bahasa Asing Nusa Mandiri \\ Jl. Ir. H. Juanda No 39, Ciputat, Tangerang \\ Email: cicih@nusamandiri.ac.id
}

\begin{abstract}
The purpose of this research is to identify how a new word is created from the usage of word formation, to understand the internal structures or forms of the word formation with their new meanings, and also to analyze types of English word formation process are used most often in the J+ Newspaper. The research uses a descriptive qualitative method; the data collection method of the research is through reading the newspaper, library research and internet research. Data analysis is using two approaches of morphological rules which are Morpheme-Based Model and Word-Based Model (theory of Haspelmath and Sims). The result of the study shows that: (1) Word formations used in J+ Newspaper, along with their forms, are 141 addition of affixes or Affixations (61\%), 7 sequences of letters or Acronyms (3\%), 8 shortening words or Clippings (3\%), 71 joining words or Compoundings (30\%), and 6 sound representation or Onomatopoeias (3\%). (2) The most word formation process, which used in the J+ Newspaper, is Affixation as 141 words (61\%) which is a common word formation process in English language. (3) All the derivational word formation are complex word and form a new meaning except clipping, a simple word from a shortening process, which means it still has the same meaning from the root but formed a new word.
\end{abstract}

Keywords: Word Formation, Affixation, Acronym, Clipping, Compounding.

\section{INTRODUCTION}

For centuries, language has an important role for human life. By using language, people will be able to express their ideas, emotions, and desires, and it is used as a medium to interact with one to another, to fulfill their daily need. Human have been using the language since they were young in order to interact with their parents, friends, and society. Furthermore, people in the world use one language, which is English, to be used as an international communication tool. English has been the most important language, as used by several mass media of the world; English has been used in order to provide certain information, normally about international issues, cultures, or lifestyles of one country.

In this research, the writer chooses one of Indonesian newspaper as his object study, which is $\mathrm{J}+$ by The Jakarta Post newspaper. Sometimes editor of this newspaper uses a complicated word formation that makes reader hard to understand, for instance, some compounding word, clipping, acronym, and so on. Since these word formations formed a new meaning, and sometimes reduction, the reader will found them as obstacles. The usage of many kinds of word formation in some headlines, articles as well as in advertisements make the writer interested to understand about types of word formation, sometimes called morphological process, and the meaning of each word.

The writer is focusing on 5 types of English word formation (Based on Zapata, 2007) which are Acronym, Affixation, Clipping, Compounding, and Onomatopoeia, including their forms, the kinds of word formation that most often used, and the new meanings which carried by each word used in the $\mathrm{J}+$ newspaper since the data which he found in the newspaper are those 5 types of word formation.

\section{RESEARCH METHOD}

In this research, the data source is $\mathrm{J}+$ newspaper by The Jakarta Post (Vol. 34. No. 106 - 2016) from page 4 to page 16 . The data of this research is word formation process which occurs in the articles and some of them carry a new meaning. This paper uses descriptive qualitative method. The data collecting method of the research is library research and the writer also collects any data that related with the thesis taken from the internet. Last but not least is data analysis technique which the writer use two approaches to morphological rules: Morpheme Based Model and Word-Based Model. The writer starts by observing through reading the articles, identifying words which contain word formation process, classifying the types of word formation, and identifying the new meaning which the words convey using a dictionary.

\section{The Definition of Morphology}

According to Lieber (2009:8), "Morphology is the study of words and word formation." From the statement above, morphology specifies its fields only on the study of words and word formation. It means that in order to understand the process of one word, which in some cases they are combined and mixed to another word; students, especially the writer, need to understand this subject to get the meaning of the word itself from the process in morphology.

\section{Morphological Forms}

Some words consist of a single morpheme which is a simple word. For instance, the word train cannot be divided into smaller parts (say, tr and ain) that carry information about its meaning or function. However, many words are said to be complex in that they contain two or more morphemes. For instance, the root word boy into complex word boy-s, act into act-ive or act-

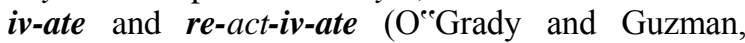
1997:133). Based on the statement above, the writer assumes that there are two forms in morphology which 
consist of simple and complex word. A simple word is a word that consists of a single, or one, morpheme and cannot be divided into smaller parts, such as the word train cannot be divided into tr and ain. On the other hand, complex word is a word that consists of two or more morphemes and can be divided into smaller parts, such as boys can be divided into boy and $-s$ which consists of the root word boy and a suffix $-s$.

\section{Morpheme}

Carstairs and McCharty (2002:16) stated that “....and morphemes can be thought of as the minimal units of morphology". The statement also explained by the writer that in morphology, there are minimal units which known as morpheme which cannot be further divided into smaller meaningful units.

\section{Word Formation}

Accordng to Plag (2002:17), "The study of wordformation can thus be defined as the study of the ways in which new complex words are built on the basis of other words or morphemes." From the statement above, word formation is a study of how new complex words are formed from the basis of other words. It means that the new words, which exist from the result of word formation, are formed as a complex word.

Furthermore, word formation can be divided into two categories, they are derivation - the formation of new lexemes - and inflection, the different grammatical word forms that make up lexemes (Lieber, 2009:8), as follows:

\section{Inflection}

Inflectional word formation is word formation that expresses grammatical distinctions like number (singular vs. plural); tense (present vs. past); person (first, second, or third); and case (subject, object, possessive), among others. It does not result in the creation of new lexemes, but merely changes the grammatical form of lexemes to fit into different grammatical contexts.

\section{Derivational}

Derivational Lexeme, or word, formation can do one of three things. It can change the part of speech (or category) of a word, such as, 'interpret' into 'interpretation' which is a transformation from verb into noun. Nevertheless, some rules of lexeme formation do not change category, but they do add substantial new meaning, such as, 'happy' to 'unhappy' which means that their category is still adjective - not changing, but the meaning is transformed from 'happy' into 'not happy'. In addition some rules of lexeme formation both change category and add substantial new meaning, such as, 'wash' into 'washable' which means that both the category and the meaning are changing from verb into adjective and change the meaning from 'wash' into 'able to be washed'.

According to Zapata (2007:4-10), there are a set of morphological processes, or also known as word formation, as listed below:

\section{Affixation}

Affixation consists in adding derivational affixes (i.e., prefixes, infixes and suffixes) to roots and stems to form new words. For example, if the suffix -able is added to the word pass, the word passable is created. Likewise, if to the word passable the prefix in- (or rather its allomorph im-) is attached, another word is formed, namely impassable. Affixation is a very common and productive morphological process in synthetic languages. In English, derivation is the form of affixation that yields new words usually by either changing the meaning and/or the part of speech (i.e., the syntactic category), or both, of the words they are attached to. In English, derivational morphemes can be either prefixes or suffixes. For example, un-+ happy (adj.) = unhappy (adj.); re-+ classify (v) = reclassify (v.); by-+ product (n.) = by-product.

\section{Compounding}

Compounding consists in the combination of two or more (usually free) roots to form a new word. For example, the word blackboard, heartfelt, brother-inlaw are compound words; they are made up of the roots (at the same time words themselves) black and board, heart and felt, brother, in and law, respectively. Compound words can be written in three different ways, as follows:

a) Open: With a space between the parts of the compound; for instance, toy store, diving board, flower pot.

b) Hyphenated: With a hyphen (-) separating the elements of the compound; for instance, flowerpot, air-brake, she-pony.

c) Solid: Without a space or hyphen between the component elements of the compound; for instance, flowerpot, washrooms, pickpocket.

Furthermore, hyphenation (separating the elements of a compound with a hyphen) is more common in British English than in American English. In American English, the tendency is to write the compounds open or solid. However, hyphenation is quite common practice in both varieties of the language when ad hoc premodifying compounds (defined as groups of words that do not occur as established compounds in the language but as a group of words that as a whole modifies another word) are used; for instance, a much-needed rest; a state-of-theart report. In addition, compounds words behave grammatically and semantically as single words. Since compound words behave as units, between their component elements no affixes (whether inflections or derivations) can usually occur; inflectional suffixes can appear only after compound words. For example, bathrooms, school buses, water resistant. Exceptions: passersby, brothers-in-law, courts-martial. Compound words usually have the primary stress on the first element of the compound; such as, 'air,crafts, 'chewing-gum. This fact differentiates compounds from phrases that have the same elements and order as compounds; phrases usually have their primary accent on the second (or nominal) element. 
Furthermore, there are a few compounds which have their primary stress on the second element as phrases; such as, working 'man, flying 'saucer, woman 'writer, fancy 'dress. The possible combinations in English compound are:

a) Compounds of two nouns $(\mathrm{N}): \mathrm{N}+\mathrm{N}=\mathrm{N}$ Sunrise, dancing girl, hand-shake, airconditioning, cigar smoker, windmill.

b) Compounds of two adjectives (Adj.): Adj. + Adj. $=$ Adj.

Gray-green, Swedish-American.

c) Compounds of an adjective (Adj.) and a noun (N): Adj. + N = N

Darkroom, highbrow.

d) Compounds of a noun (N) and an adjective (Adj.): $\mathrm{N}+$ Adj. = Adj. Airsick, bottle-green.

e) Compounds of a pronoun (Pron.) and a noun (N): Pron. $+\mathrm{N}=\mathrm{N}$

She-pony, he-goat.

f) Compounds of a preposition (Prep.) and a verb (V): Prep. $+\mathrm{V}=\mathrm{V}$ Overtake, undergo

g) Compounds of a preposition (Prep.) and a noun (N): Prep. $+\mathrm{N}=\mathrm{N}$ Onlooker, off-day.

h) Compounds of a noun $(\mathrm{N})+$ and a verb $(\mathrm{V})=$ Adj. Man-eating, ocean-going, heartfelt.

i) Compounds of an adjective/adverb (Adj./Adv.) + and a verb $(\mathrm{V})=$ Adj.

Hard-working, good-looking, dry-cleaned.

j) Compounds of a noun (N) + and a Preposition (Prep.) $=\mathrm{N}$ Passer-by, hanger-on.

k) Compounds of verb (V) + and an adverb (Adv.) or prepositional (Prep.) $=\mathrm{N}$ Show-off, holdup.

l) Compounds of a verb (V) + and an adverb (Adv.) $=\mathrm{N}$

have-not, get-together.

\section{Symbolism}

Symbolism (or morpheme internal change) consists in altering the internal phonemic structure of a morpheme to indicate grammatical functions. For example, in order to form the plurals of goose \gu:s〉 and tooth $\backslash \mathrm{tu}: \Theta \backslash$ in English, the phoneme $\langle\mathrm{u}: \backslash$ is replaced by the phonemeli: $\backslash$, thus yielding the plural forms geese \gi:s\ and teeth $\backslash \mathrm{ti}: \Theta \backslash$, respectively. Similarly, a few verbs indicate their past tense and past participle forms just by undergoing internal changes, as in the following cases:

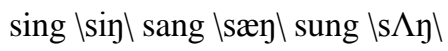

swim \swim\swam \swæm\swum \sw $\Lambda \mathrm{m} \backslash$

\section{Reduplication}

Reduplication consists in the repetition of all or of part of a root or stem to form new words. If the entire root or stem is repeated, the process is called complete (or total) reduplication, and the new word is considered as a repetitive compound. Total reduplication is fairly frequent in Indonesian, for instance, in Indonesian, total reduplication is used to form the plural of nouns, as in [rumah] 'house', [rumahrumah] 'houses'; [ibu] 'mother' [ibuibu] 'mothers'; [lalat] 'fly', [lalatlalat] 'flies'.

\section{Suppletion}

Suppletion consists in a complete change in the form of a root (i.e., a word) or in the replacement of root by another morphologically unrelated root with the same component of meaning in different grammatical contents, for instance, good and well change to better and best in the comparative and superlative. Similarly, bad and badly change to worse and worst. Likewise, a ' $b e$ ' change to am, are, and is in the present; am/is change to was and are to were in the past.

\section{Acronym}

Acronym is the process whereby a new word is formed from the initial letters of the constituent words of a phrase or sentence. Furthermore, there are two main types of acronyms, namely:

a. Acronyms which are pronounced as a word; for instance NASA / 'næsə/ (= National Aeronautics and Space Administration), radar / 're da:r/ radar (radio detecting and ranging), UNESCO / ju:'neskəo/ (= United Nations Educational, Scientific and Cultural Organization), BASIC / 'beisık/ (= Beginners' All-purpose Symbolic Instruction Code), COBOL / 'kəubol/ (= Common Business Oriented Language), and so on.

As can be seen, acronyms of this type often derive from phrasal names. Many of them belong to the jargon (specialized language) of particular occupations, organizations or fields of study (especially scientific, administrative, and political) and might be completely meaningless to the persons who are not familiarized with them. Notice also that some of these acronyms are of so frequent an occurrence that people often use them without the slightest idea of what the words stand for; for instance, laser, radar.

b. Acronyms which are pronounced as sequences of letters (also called 'alphabetisms'); for instance, C.O.D. / , si:əひ'di:/ (= cash on delivery), MIT / ,emai'ti:/ $\quad(=$ Massachusetts Institute of Technology), VIP / , vi:ar'pi:/ (= very important person). In writing, the more institutionalized formations have no periods between their component letters. This tendency is especially more common in British English than in American English; e.g., DIY / di:ai'wai/ (= do-it-yourself), FBI / ,efbi:'aI/ (= Federal Bureau of Investigations).

Furthermore, each constituent letter of these acronyms usually represents a full word or constituent in the compound, or just a part of a word, as in the following examples: $T B$ / ,ti: 'bi:/ (= tuberculosis), TV/,ti: 'vi:/ (= television). Likewise, notice that some of these 
acronyms are given a quasi-phonetic written form; for instance Emcee for M.C. (= Master of Ceremonies), Deejay for DJ (= disc jockey), and so on.

\section{Clipping}

Clipping is the processes whereby new words are formed by shortening other words; by eliminating the initial part, the last part, or both parts, of those words. For instance, phone from (tele)phone, plane from (air)plane, ad from ad(vertisement), exam from exam(ination), flu from (in)flu(enza), fridge from refrigerator, another examples are:

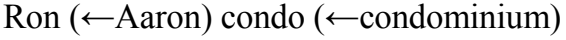

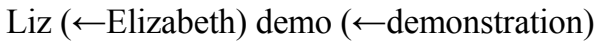

$$
\begin{aligned}
& \text { Mike ( } \leftarrow \text { Michael) disco ( } \leftarrow \text { discotheque) }
\end{aligned}
$$

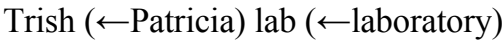

\section{Blending}

Blending is the process whereby new words are formed by combining parts of two words, usually the beginning of one word and the end of another, for example, smog (smoke + fog), brunch (breakfast + lunch), heliport (helicopter + airport), motel (motor + hotel), FORTRAN (formula translation), and so on. Following is a partial list of other common blends: breathalyzer (breath + analyzer), electrocute (electro + execute), Eurovision (European + television), multiversity (multiple + university), newscast (news + broadcast), paratroops (parachute + troops), telecast (television + broadcast), travelogue (travel + catalogue), telex (teleprinter + exchange).

\section{Borrowing}

Borrowing is the process whereby new words are formed by adopting words from other languages together with the concepts or ideas they stand for. For instance, tango, mango, taco, and burrito that borrowed from Spanish; fiancé, very (adapted from Old French verai), garage from French; pizza, mafia from Italian; and so on.

\section{Back-formation}

Back-formation is the process by which new words are formed by the deletion of a supposed affix from an already existing word. For example, the verbs peddle, edit, hawk, enthuse, stoke, swindle, televise, donate, sculpt, buttle have been created form the pre-existing nouns peddler, editor, hawker, enthusiasm, stoker, swindler, television, donation, sculptor and butler, respectively.

\section{Word Coinage}

Word coinage (or invention) is the process whereby new words are created outright, either deliberately or accidentally, to fit some purpose. Usually, words are coined to express new ideas, processes, products, etc. in the language, for instance, brand names such as Xerox, Kodak, Exxon, and Kleenex. These products, which once a new product, come to be used as common nouns.

\section{Functional Shift}

Functional shift (conversion or zero derivation) is the process by which new words are created by using a word in new functions (by shifting, changing or converting its original grammatical class to another class), without any change in its form. For example, when the word water is used in the following sentence Give me some water, please it is used as a noun, which is probably its original (and more common) use. But when water is used in the sentence, The children water the plants every morning, it is used in a new syntactic function, namely, as a verb, and no change in spelling or pronunciation has been made. In other words, the grammatical category of the word water has shifted from noun to verb.

\section{Morphological Analysis}

Haspelmath and Sims (2010:3) stated "It is often suggested that morphological analysis primarily consists in breaking up words into their parts and establishing the rules that govern the co-occurrence of these parts.” From the statement, a morphological analysis must have some criterion such as a complex word to be observed, a process of breaking up words into smaller parts, and also analysing some rules which could explain the phenomenon of morphemes.

Morphological analysis typically consists of the identification of parts of words, or, more technically, constituents of words. We can say that the word nuts consists of two constituents: the element nut and the element s. In accordance with a widespread typographical convention, we will often separate word constituents by a hyphen: nut-s. It is often suggested that morphological analysis primarily consists in breaking up words into their parts and establishing the rules that govern the co-occurrence of these parts. The smallest meaningful constituents of words that can be identified are called morphemes. In nut-s, both $-s$ and nut are morphemes. Other examples of words consisting of two morphemes would be break-ing, hope-less, re-write, cheese-board; words consisting of three morphemes are re-writ-ing, hope-less-ness, earplug-s; and so on. It would make morphology quite similar to syntax, which is usually defined as 'the study of the combination of words to yield sentences'.

\section{Two Approaches to Morphological Rules}

There are two approaches in order to deal with the phenomenon which happens in Morphology which stated by Haspelmath and Sims (2010:41):

\section{Morpheme-Based Model}

The morpheme-based model is associated with the morpheme-combination approach to morphology: 'Morphology is the study of the combination of morphemes to yield words'. In this approach method, it is emphasizes on the connection within the combination of morpheme which means a word must be analyzed by breaking it into its smaller units in order to find out the process within the word. We can use these word-structure rules to create complex 
words. In the following, we see the individual steps by which the words bags, unhappier and cheeseboard can be created using the rules:

- Word-form $\rightarrow$ Derivational Prefix + stem + inflectional suffix

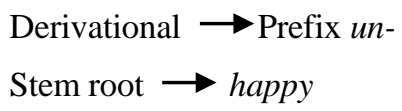

Inflectional suffix $\rightarrow-$ er

Word-form: un-happi-er

- Word-form $\rightarrow$ Stem

Stem $\rightarrow$ Stem + stem
Stem $\rightarrow$ Root
Root $\rightarrow$ Cheese
Root $\rightarrow$ Board

Stem: cheese-board

Word-form: cheese-board

\section{Word-Based Model}

In the word-based model, the fundamental significance of the word is emphasized and the relationship between complex words is captured not by splitting them up into parts and positing a rule of concatenation, but by formulating word-schemas (contains information on pronunciation, syntactic properties and meaning.) that represent the features common to morphologically related words.

For instance, the similarities among the English words bags, keys, gods, ribs, bones, gems (and of course many others) can be expressed in the word schema:

a. Words: bags, keys, gods, ribs, bones, gems, ...

b. Lexical entries for words

[/bægz/ N] [/khijz/ N] [/gadz/N] [/ribz/N]

$\left[\right.$, ,bags $\left.{ }^{\mathrm{ee}}\right]\left[,\right.$, keys $\left.^{\mathrm{ec}}\right]\left[,\right.$, gods $\left.^{\mathrm{ee}}\right]\left[, \mathrm{ribs}^{\mathrm{ee}}\right]$

c. Word-schema

[/Xz/ N]

[,plurality of $\mathrm{xs}^{\mathrm{ee}}$ ]

From the statement above from Haspelmath and Sims, the writer concludes that the morphological analysis is similar to syntax which consists in breaking up words into their parts and establishing the rules that govern the co-occurrence of these parts. Furthermore, the writer uses the Morpheme-Based Model Approaches which emphasizes on the connection within the combination of morpheme which means a word must be analysed by breaking it into its smaller units in order to find out the process within the word.

\section{Meaning}

According to Lamb in Hill (1969:45): The area of linguistic structure which is studied under the headings of lexicology and semantics, if I describe it very simply, is concerned with words and their meanings. Some of the phenomena, which must be accounted for in this area, are these: (1) A word can have more than one meaning. An example is the English word table, which can designate either a piece of furniture or a type of display of information on the page of a book. (2) Different words can have the same meaning or example big and large. (3) The meanings of some words can be analysed into components. For example, the English word mare, can be analysed into the components female and horse; similarly, doe has the components female and deer, and hen has the components female and chicken. (4) Certain combinations of words have meanings which are different from the combinations of their separate meanings. An example is blow up, meaning "destroy by explosion", as in the bomb blew up the building. (5) Some pairs of words have opposite meanings. An example is the pair big and little. (6) The meanings of some words are included in the meanings of others. Or example, the meaning of plant is included in that of tree, and the meaning of tree is included in that of oak.

While the morphology concerned with the structure of words including its shape or formation, semantic focuses its study on words and their meaning. This study of words and meaning is related to each other; since in order to understand and to use the words properly, people need not only to understand how the words are formed but also the meaning that attached with them. The importance of meaning is stated by Lamb on point 1 which explained that a word in English can have more than one meaning. Furthermore, as point number 4 shows that certain combinations of words have a different meaning from their separate meanings. For instance, the word blow up, which has meaning as "destroy by explosion”, has a different meaning from their separate form blow and up.

\section{RESULT AND DISCUSSION}

The writer found and analyzed 5 (five) types of word formation used in J+ Newspaper to help in identifying how a new word is created, to understand the internal structure of the word formation, and also to acknowledge a new meaning which carried by a word formation. The 5 types consists of Acronym, Affixation, Clipping, Compounding, and Onomatopoeia, including their forms, the kinds of word formation that most often used, and the new meanings which carried by each word.

\section{Data Presentation and Analysis of Word Formation}

In this part the writer presented the data and analyzes the word formation in $\mathrm{J}+$ newspaper using the two approaches to morphological rules: Morpheme Based Model and Word-Based Model. The writer start from collecting the data, then formulating wordschemas (contains information on pronunciation, syntactic properties and meaning) which represent the features common to morphologically related words, breaking them into their smaller units in order to find 
out the process within the word, and also double check the new meaning using dictionary.

\section{Affixation}

In this part the writer presented the data that have been analyzed which is the word formation in $\mathrm{J}+$ newspaper by The Jakarta Post newspaper (VOL 34. NO. 106 - 2016).

Table 1. Affixation

\begin{tabular}{|c|c|c|}
\hline No & Words & Explanation \\
\hline \multirow[t]{3}{*}{1.} & Culture & $\begin{array}{l}\text { The word 'Cultural' is a part of } \\
\text { affixation because it can be divided into } \\
\text { its smaller forms. The word 'Cultural' } \\
\text { has } 2 \text { morphemes which are Culture (N) } \\
+ \text {-al (Suffix) = Cultural (Adj.). It } \\
\text { consists of } 1 \text { free morpheme and } 1 \\
\text { bound morpheme, which are: }\end{array}$ \\
\hline & & 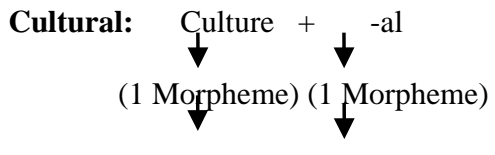 \\
\hline & & FM $\quad$ BM \\
\hline
\end{tabular}

The word 'Culture' is free morpheme because it can stand alone as a word, which has meaning as all the knowledge and values shared by a society. In contrast, '-al' is bound morpheme since it cannot stand alone as a word and it is called suffixation as a process of affixation which placed in the end of word. Furthermore, when combined together, 'Cultural' forms a new grammatical category as an Adjective, and has a new meaning as 'of or relating to the arts and manners that a group favours.'

2. $\quad$ Festival The word 'Festival' is a part of affixation because it can be divided into its smaller forms. The word 'Festival' has 2 morphemes which are Festive (Adj.) + -al (Suffix) = Festival $(\mathrm{N})$. It consists of 1 free morpheme and 1 bound morpheme, which are:

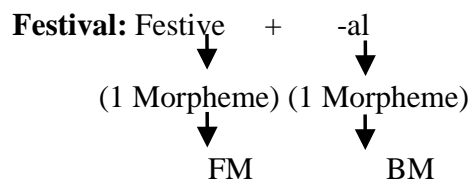

'Festive' is free morpheme because it can stand alone as a word, which has meaning as offering fun and gaiety. In contrast, '-al' is bound morpheme since it cannot stand alone as a word and it is called suffixation as a process of affixation which placed in the end of word. Furthermore, when combined together, 'Festival' forms a new grammatical category as a Noun, and has a new meaning as 'an organized

\begin{tabular}{|c|c|c|}
\hline & & $\begin{array}{l}\text { series of acts and performances } \\
\text { (usually in one place).' }\end{array}$ \\
\hline 3. & Fearless & $\begin{array}{l}\text { The word 'Fearless' is a part of } \\
\text { affixation because it can be divided } \\
\text { into its smaller forms. The word } \\
\text { 'Fearless' has } 2 \text { morphemes which are } \\
\text { Fear (N) + -less (Suffix) = Fearless } \\
\text { (Adj.). It consists of } 1 \text { free morpheme } \\
\text { and } 1 \text { bound morpheme, which are: }\end{array}$ \\
\hline
\end{tabular}

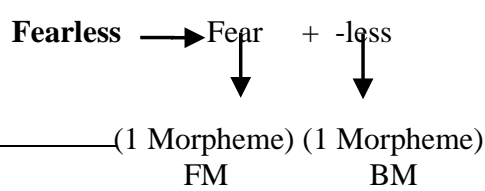

The word 'Fear' is free morpheme because it can stand alone as a word, which has meaning as an emotion experienced in anticipation of specific pain or danger. In contrast, '-less' is bound morpheme since it cannot stand alone as a word and it is called suffixation as a process of affixation which placed in the end of word. Furthermore, when combined together, 'Fearless' forms a new grammatical category as an Adjective, and has a new meaning as 'invulnerable to fear or intimidation.'

4. Available The word 'Available' is a part of affixation because it can be divided into its smaller forms. The word 'Available' has 2 morphemes which are Avail (N) + -able (Suffix) = Available (Adj.). It consists of 1 free morpheme and 1 bound morpheme, which are:

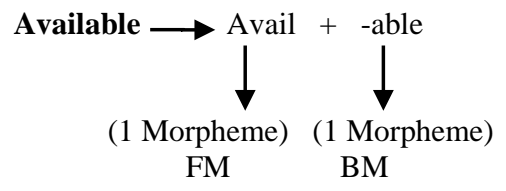

The word 'Avail' is free morpheme because it can stand alone as a word, which has meaning as use to one's advantage; be useful to. In contrast, 'able' is bound morpheme since it cannot stand alone as a word and it is called suffixation as a process of affixation which placed in the end of word. Furthermore, when combined together, 'Available' forms a new grammatical category as an Adjective, and has a new meaning as 'obtainable or accessible and ready to use or service.'

\section{Acronym}

Table 2. Acronym

No. Words Explanation




\begin{tabular}{|c|c|c|}
\hline \multirow[t]{3}{*}{1.} & \multirow[t]{3}{*}{ UNICEF } & $\begin{array}{l}\text { UNICEF is called acronym } \\
\text { because it is formed by making } \\
\text { initial letter of the words and } \\
\text { are pronounced it as a word. } \\
\text { The word 'UNICEF' is an } \\
\text { acronym of 'United Nations } \\
\text { International Children's } \\
\text { Emergency Fund' }\end{array}$ \\
\hline & & $\begin{array}{l}\text { The word 'United' has a } \\
\text { meaning become one, } \\
\text { meanwhile, the word 'Nations' } \\
\text { carries a meaning of a } \\
\text { federation of tribes, the word } \\
\text { 'International' has a meaning } \\
\text { of concerning to all or at least } \\
\text { two or more nations, the word } \\
\text { 'Children' has a meaning of a } \\
\text { young person, 'Emergency' } \\
\text { has a meaning of a sudden } \\
\text { unforeseen crisis, and 'Fund' } \\
\text { means a reserve of money set } \\
\text { aside for some purpose. }\end{array}$ \\
\hline & & $\begin{array}{l}\text { Furthermore, when combined } \\
\text { together the word 'UNICEF' } \\
\text { carries a new meaning of an } \\
\text { agency of the United Nations } \\
\text { responsible for programs to aid } \\
\text { education and the health of } \\
\text { children and mothers in } \\
\text { developing countries. }\end{array}$ \\
\hline & \multirow[t]{2}{*}{ a.m. } & $\begin{array}{l}\text { The word 'am' or 'a.m.', refers } \\
\text { to time not a 'to be', is an } \\
\text { acronym of 'Ante Meridiem'. It } \\
\text { is called as acronym because it } \\
\text { is formed by taking the initial } \\
\text { letters of the words and } \\
\text { pronouncing them as sequences } \\
\text { of letters. }\end{array}$ \\
\hline & & $\begin{array}{l}\text { The word 'Ante' is a prefix } \\
\text { which has a meaning of behind, } \\
\text { before. 'Meridiem' has a } \\
\text { meaning of noon; when } \\
\text { combined together, the word } \\
\text { 'a.m.' carries a meaning of } \\
\text { before noon. }\end{array}$ \\
\hline & \multirow[t]{2}{*}{ DJ } & $\begin{array}{l}\text { The word DJ is an acronym of } \\
\text { 'Disc Jockey'. It is called as } \\
\text { acronym because it is formed } \\
\text { by taking the initial letters of } \\
\text { the words and pronounced as } \\
\text { sequences of letters. }\end{array}$ \\
\hline & & $\begin{array}{l}\text { Furthermore, the word 'Disc' } \\
\text { has a meaning something with } \\
\text { a round shape resembling a flat } \\
\text { circular plate, meanwhile, the } \\
\text { word 'Jockey' carries a } \\
\text { meaning of an operator of } \\
\text { some vehicle, machine or } \\
\text { apparatus; and when combined } \\
\text { together the word 'DJ' carries a } \\
\text { new meaning of a person who } \\
\text { announces and plays popular } \\
\text { recorded music. }\end{array}$ \\
\hline
\end{tabular}

\begin{tabular}{ll}
\hline $4 . \quad$ VIP & The word VIP is an acronym of \\
'Very Important Person'. It is \\
called as acronym because it is \\
formed by taking the initial \\
letters of the words and \\
pronounced as sequences of \\
letters.
\end{tabular}

Furthermore, the word 'Very' has a meaning used as an intensifier, meanwhile, the word 'Important' carries a meaning of great significance or value, and 'Person' has a meaning of a human being. When combined together the word 'VIP' carries a new meaning of an important or influential person.

$\begin{array}{ll}\text { 5. UNESCO } & \text { UNESCO is called acronym } \\ \text { because it is formed by making }\end{array}$
initial letter of the words and are pronounced it as a word. The word 'UNESCO' is an acronym of 'United Nations Educational Scientific and Cultural Organization’

The word 'United' has a meaning become one, meanwhile, the word 'Nations' carries a meaning of a federation of tribes, the word 'Educational' has a meaning of relating to the process of education, 'Scientific' has a meaning of relating to the practice of science, the word 'Cultural' has a meaning of relating to the shared knowledge and values of a society, and 'Organization' means a group of people who work together for an explicit purpose.

Furthermore, when combined together the word 'UNICEF' carries a new meaning of an agency of the United Nations that promotes education and communication and the arts.

$\begin{array}{lll}\text { 6. GPS } & \text { The word GPS is an acronym } \\ \text { of 'Global Positioning }\end{array}$
System'. It is called as acronym because it is formed by taking the initial letters of the words and pronounced as sequences of letters.

Furthermore, the word 'Global' has a meaning not limited or provincial in scope, meanwhile, the word 'Positioning' carries a meaning of the act of putting something in a certain place, and 


\begin{tabular}{l}
\hline 'System' has a meaning of a \\
group of independent but \\
interrelated elements \\
comprising a unified whole. \\
When combined together the \\
word 'VIP' carries a new \\
meaning of a navigational \\
system involving satellites and \\
computers that can determine \\
the latitude and longitude of a \\
receiver on Earth. \\
The word US is an acronym of \\
'United States'. It is called as \\
acronym because it is formed \\
by taking the initial letters of \\
the words and pronounced as \\
sequences of letters. \\
Furthermore, the word 'United' \\
has a meaning become one, \\
meanwhile, the word State \\
carries a meaning of the \\
territory occupied by one of the \\
constituent administrative \\
districts; and when combined \\
together the word 'US' carries \\
a new meaning of North \\
American republic containing \\
50 states; America. \\
\hline
\end{tabular}

\section{Clipping}

Table 3. Clipping

\begin{tabular}{|c|c|c|}
\hline No. & Words & Explanation \\
\hline 1. & Aug & $\begin{array}{l}\text { The word 'Aug' is called clipping } \\
\text { since it is the processes whereby } \\
\text { new words are formed by } \\
\text { shortening other words; by } \\
\text { eliminating the last part of the } \\
\text { word 'Aug(ust)' which means the } \\
\text { month following July and } \\
\text { preceding September. It consist } \\
\text { only } 1 \text { morpheme. }\end{array}$ \\
\hline 2. & Oct & $\begin{array}{l}\text { The word 'Oct' is called clipping } \\
\text { since it is the processes whereby } \\
\text { new words are formed by } \\
\text { shortening other words; by } \\
\text { eliminating the last part of the } \\
\text { word 'Oct(ober)' which means the } \\
\text { month following September and } \\
\text { preceding November. It consist } \\
\text { only } 1 \text { morpheme. }\end{array}$ \\
\hline 3. & Photo & $\begin{array}{l}\text { The word 'Photo' is called } \\
\text { clipping since it is the processes } \\
\text { whereby new words are formed by } \\
\text { shortening other words; by } \\
\text { eliminating the last part of the } \\
\text { word 'Photo(graph)' which means } \\
\text { a static picture taken by camera, } \\
\text { recorded by focusing light onto a } \\
\text { light-sensitive surface. It consist } \\
\text { only } 1 \text { morpheme. }\end{array}$ \\
\hline 4. & Com (.com) & $\begin{array}{l}\text { The word '.com', which is a jargon } \\
\text { word - specialized language of } \\
\text { particular occupations, in this case } \\
\text { is a computer jargon which means }\end{array}$ \\
\hline
\end{tabular}

\begin{tabular}{ll}
\hline & top level domain for commerce, is \\
& a clipped word since the process of \\
& shortening occurs and shortens 3 \\
& syllables of word 'Com(mercial)' \\
& into 1 syllable 'Com'. It consist \\
& only 1 morpheme. \\
\hline 5. Ad $\quad$ The word 'Ad', which means a \\
public promotion of some product \\
or service, is a clipped word since \\
the process of shortening occurs \\
and shortens 4 syllables of word \\
'Ad(vertisement)' into 1 syllable \\
'Ad'. It consist only 1 morpheme. \\
\hline Ammo & The word 'Ammo' is also a \\
& clipping word since it is derived \\
& from the word 'Amm(uniti)o(n)' \\
& which means it shortens the \\
& polysyllabic word that originally \\
& has 4 syllables into just 2 syllables. \\
& In order words, by deleting 2 \\
& syllables the word 'Ammo' is \\
& appeared and has a meaning as \\
projectiles to be fired from a gun. \\
It consist only 1 morpheme.
\end{tabular}

\section{Compounding}

Table 3. Compounding

\begin{tabular}{|c|c|c|}
\hline No & Words & Explanation \\
\hline 1. & Moonlight & $\begin{array}{l}\text { The word 'Moonlight' is compounding } \\
\text { because it is a joining of two separated } \\
\text { words to produce a single word. } \\
\text { Furthermore it is a compounding since } \\
\text { the words are joined together in solid } \\
\text { form of compounding, and it carries a } \\
\text { new meaning as 'the light of the moon'; } \\
\text { when joined together as a compound, it } \\
\text { comes up as a Noun (Compound } \\
\text { Noun). There are two words in the } \\
\text { same grammatical category 'Moon' } \\
\text { (N) + 'Light' (N). This word has } 2 \\
\text { morphemes which all of them are free } \\
\text { morphemes. As shown below: } \\
\text { Moon + } \downarrow \\
\text { (1 Morpheme) (1 Morpheme) }\end{array}$ \\
\hline
\end{tabular}




\begin{tabular}{|c|c|c|}
\hline No & Words & Explanation \\
\hline & & FM \\
\hline \multirow[t]{2}{*}{2.} & \multirow[t]{2}{*}{ Getaway } & $\begin{array}{l}\text { The word 'Getaway' is compounding } \\
\text { because it is a joining of two separated } \\
\text { words to produce a single word. } \\
\text { Furthermore it is a compounding since } \\
\text { the words are joined together in solid } \\
\text { form of compounding, and it carries a } \\
\text { new meaning as 'a rapid escape'; } \\
\text { when joined together as a compound, it } \\
\text { comes up as a Noun (Compound } \\
\text { Noun). There are two words in the } \\
\text { different grammatical category 'Get' } \\
\text { (V) + 'Away' (Adv.). This word has } 2 \\
\text { morphemes which all of them are free } \\
\text { morphemes. As shown below: }\end{array}$ \\
\hline & & $\underset{\downarrow}{\text { Get }}+\underset{\downarrow}{\downarrow}$ \\
\hline
\end{tabular}

Onomatopoeia

Table 4. Onomatopoeia

\begin{tabular}{|c|c|c|}
\hline No. & Words & Explanation \\
\hline \multirow[t]{3}{*}{1.} & Wowed & $\begin{array}{l}\text { The word 'Wowed' is called } \\
\text { onomatopoeia because it is a word } \\
\text { whose sound represents an aspect } \\
\text { of the thing that they name, in this } \\
\text { case represents a sound of } \\
\text { impression. The word 'Wowed' } \\
\text { has } 2 \text { morphemes, } 1 \text { free } \\
\text { morpheme and } 1 \text { bound } \\
\text { morpheme, which are: }\end{array}$ \\
\hline & & $\begin{array}{l}\text { Wowed Wow }+ \text { (-ed) } \\
\text { (1Morpheme) (1 Morpheme) }\end{array}$ \\
\hline & & $\begin{array}{l}\text { FM } \\
\text { The word 'Wowed' has a } \\
\text { grammatically function as a V (V) } \\
\text { and has a meaning as impress } \\
\text { greatly. }\end{array}$ \\
\hline \multirow[t]{3}{*}{2.} & Hey! & $\begin{array}{l}\text { The word 'Hey!' is called } \\
\text { onomatopoeia because it is a word } \\
\text { whose sound represents an aspect } \\
\text { of the thing that they name, in this } \\
\text { case represents a sound of } \\
\text { greeting. The word 'Hey' has only } \\
1 \text { free morpheme: }\end{array}$ \\
\hline & & Hey \\
\hline & & $\begin{array}{l}\text { The word 'Hey!' has a } \\
\text { grammatically function as a } \\
\text { Interjection and has a meaning as } \\
\text { used as a greeting; used to get } \\
\text { someone's attention. }\end{array}$ \\
\hline
\end{tabular}

\begin{tabular}{ll}
\hline 3. Whoa & The word 'Whoa' is called \\
onomatopoeia because it is a word \\
whose sound represents an aspect \\
of the thing that they name, in this \\
case represents a sound of \\
instruction. The word 'Whoa' has \\
only 1 free morpheme:
\end{tabular}

Whoa

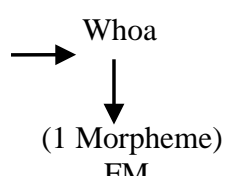

FM

The word 'Whoa' has a grammatically function as an Interjection and has a meaning as instruction to stop.

\begin{tabular}{|c|c|}
\hline \multirow[t]{3}{*}{ 4. $\quad$ Bang } & $\begin{array}{l}\text { The word 'Bang' } \\
\text { onomatopoeia because } \\
\text { whose sound represents } \\
\text { of the thing that they na } \\
\text { case represents a sour } \\
\text { shooting. The word ' } \\
\text { only } 1 \text { free morpheme: }\end{array}$ \\
\hline & Bang $\longrightarrow$ Bang \\
\hline & $\begin{array}{c}\text { (1 Morpheme) } \\
\text { FM }\end{array}$ \\
\hline
\end{tabular}

The word 'Bang' has a grammatically function as a Noun (N) and has a meaning as $A$ sudden very loud noise.

5. Oh The word 'Oh' is called onomatopoeia because it is a word whose sound represents an aspect of the thing that they name, in this case represents a sound of amazement. The word 'Ooh' has only 1 free morpheme:

Oh

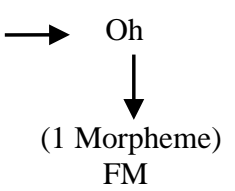

The word 'Oh' has a grammatically function as a Interjection and has a meaning as expresses appreciation, amazement, surprise and other emotions.

6. Buzz The word 'Buzz' is called
onomatopoeia because it is a word whose sound represents an aspect of the thing that they name, in this case represents a sound of bees. The word 'Buzz' has only 1 free morpheme:

Buzz $\longrightarrow$ Buzz 


\begin{tabular}{l} 
(1 Morpheme) \\
FM \\
$\begin{array}{l}\text { The word 'Buzz' has a } \\
\text { grammatically function as a Verb } \\
\text { (V) and has a meaning as make a } \\
\text { buzzing sound. }\end{array}$ \\
\hline
\end{tabular}

From the data above, the writer may give a conclusion that Derivational Affixation is the addition of derivational affixes to roots and stems to form new words, such as Culture $(N)+-a l$ (Suffix) = Cultural (Adj.). This process produces new meaning since the addition of suffix helps to form a new word, and sometimes a new grammatical category, which its meaning may totally different from the meaning that its root carry. For example, the root 'Culture' has a meaning of 'all the knowledge and values shared by a society'. In contrast, when there is a suffix '-al' attached to the root, it becomes 'Cultural' which has a new meaning as 'of or relating to the arts and manners that a group favours.'

Furthermore, Acronym is formed from taking the initial letter of some or all of the words in a phrase or sentence and can be pronounced as a word or might be pronounced as sequences of letters, for example, US is an acronym of 'United States.' This process produces new meaning since the meaning of the phrase which is in the acronym words will be differed from the meaning of its root words when they are divided. For example, the words 'United' and 'States' have meaning as become one and the other means the territory occupied by one of the constituent administrative districts. Furthermore, when 'United' and 'States' are combined into US, it has a new meaning as North American republic containing 50 states; America. Whereas, clipping is formed from a shortening process, in which 1 or more syllables are deleted, such as the word Ad from the word Ad(vertisement). This process does not produce new meaning since the clipped words occurred from the process of shortening an existing word which means that the meaning remains the same; even though the clipped words create a new form (word). Both 'Ad' and 'Advertisement' have a meaning of ' $a$ public promotion of some product or service.'

Meanwhile, compounding is formed from the combination process of two or more words to form a new word with a new meaning from their separated form, such as Upload, in this case has a meaning of 'transfer a file or program to a central computer from a smaller computer'. The meaning of compound word is different from the meaning of their separated meaning which the word ' $U p$ ' has a meaning of to a 'higher intensity' and 'Load' has a meaning of 'fill or place a load on'.

And the last is onomatopoeia which is formed from a word whose represents an aspect of the thing that they name, such as wowed which represents a sound of impression. This process produces new meaning since the meaning of the word comes from the adaptation of the sound aspect of one thing; the words imitate the sound they denote. For example, Wowed which represents a sound of impression is produced by the imitation of the sound that the word denote, therefore a new meaning of 'impress greatly' appeared.

\section{Data Analysis of Word Formation Usage}

From the data, the writer found that there are 233 derivational word formations in $\mathrm{J}+$ newspaper by The Jakarta Post (VOL 34. NO. 106 - 2016) from page 4 until 16, which some of them are complex words except clipping which is simple word. The 233 word formations that found consist of 141 Affixations, 7 Acronyms, 8 Clippings, 71 Compounds, and 6 Onomatopoeia words.

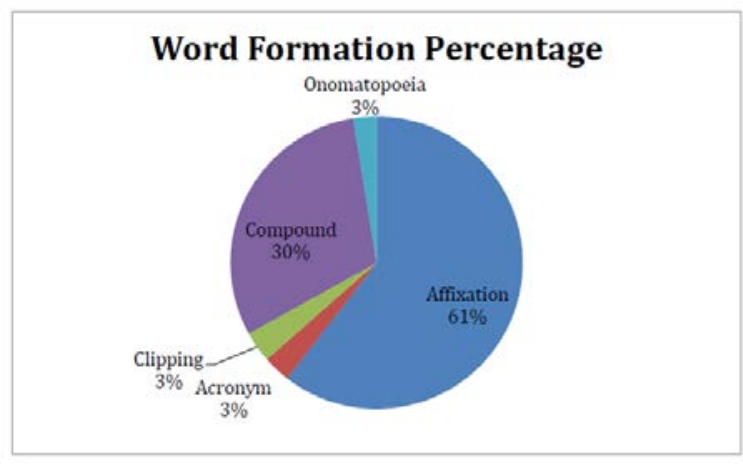

Figure 1. Word Formation Percentage

The percentages show that the most word formation process, which used in the $\mathrm{J}+$ Newspaper, is Affixation word (61\%). Furthermore the writer also found out that affixation is the most common word formation process, based on findings both from newspaper and also dictionaries, since this process is the most common and productive morphological process; It is also the easiest way to form a new word with a new meaning.

\section{CONCLUSION}

Based on the analysis of data, the writer can make conclusion as follows: firstly, there are 233 word formations which consists of 5 types of English word formations process used in $\mathrm{J}+$ newspaper by The Jakarta Post (VOL 34. NO. 106 - 2016) page 4 until 16. The 5 types of English word formations are 141 Affixation (61\%), 7 Acronym (3\%), 8 Clipping (3\%), 71 Compound (30\%), and 6 Onomatopoeia (3\%) words. As a result, the word formation process that is used in J+ newspaper by The Jakarta Post mostly Affixation, with its form as addition of derivational affixes to roots and stems to form new words, for about $61 \%$ or 141 affixations.

Furthermore, all the derivational word formation are complex word and form a new meaning except clipping which is simple word and just a shortening process which means it still has the same meaning 
from the root but formed a new word. Derivational Affixation produces new meaning since the addition of suffix, prefix, or circumfix helps to form a new word, and sometimes a new grammatical category, which its meaning is may totally different with the meaning that its root carry. Acronym produces new meaning since the meaning of the phrase which is in the acronym words will be differed from the meaning of its root words when they are divided. Meanwhile, Clipping does not produce new meaning since the clipped words occurred from the process of shortening an existing word which means that the meaning remains the same; even though the clipped words create a new form (word). Compounding, in contrast, produces a new meaning from the combination of two or more words which will be different from their separated forms or roots. Lastly, onomatopoeia produces new meaning since the meaning of the word comes from the adaptation of the sound aspect of one thing; the words imitate the sound they denote.

\section{REFERENCES}

Aronoff, Mark, and Kirsten Fudeman. (2011). Fundamental of Linguistics: What Is Morphology?. 2nd ed. United Kingdom: Willey-Blackwell.

Carstairs, Andrew and McCarthy. (2002). An Introduction To English Morphology: Words And Their Structure. United Kingdom: Edinburgh University Press, Ltd.

Haspelmath, Martin and Sims. (2010). Understanding Language Series: Understanding Morphology. 2nd ed. United Kingdom: Hodder Education.
Hill, Archibald. A. (1969). Voice Of America Forum Series: Linguistics. Washington, D.C.: Voice Of America.

J+ Newspaper. (2016). Your Weekly Lifestyle Supplement. Jakarta: J+ by The Jakarta Post, VOL 34. NO. 106 - 2016. (September 3, 2016)

Lieber, Rochelle. (2009). Introducing Morphology. New York: Cambridge University Press.

Meyer, Charles. F. (2009). Introducing English Linguistics. New York: Cambridge University Press.

O’Grady, William, Michael Dobrovolsky and Francis Katamba. (1997). Contemporary Linguistics: An Introduction. Adapted Version. Adisson Wesley Longman, Ltd.

Oxford Advanced Learner's Dictionary. 7th ed. Oxford University Press

Plag, Ingo. (2002). Word-Formation In English. Draft Version. Cambridge University Press. Available from http://www2.unisiegen.de/ engspra/plag-in-press.pdf (May 8, 2015)

Yule, George. (2010). The Study of Language. 4th Ed. New York: Cambridge University Press.

Zapata, Argenis. A. (2007). Unit 1: Types Of Words And Word-Formation Processes In English. Universidad de Los Andes. Available from http://webdelprofesor.ula.ve/humanidades/az apata/materias/english_4/unit_1_types_of_w ords_and_word_formation_processes.pdf (May 8, 2015) 